\title{
RELATOS DE MÃES COM BEBÊS INTERNADOS EM UTI NEONATAL SOBRE RELAÇÕES FAMILIARES E CONJUGAIS
}

\author{
REPORTS FROM MOTHERS WITH NEWBORNS IN INTENSIVE CARE TREAT- \\ MENT ABOUT FAMILIAL AND CONJUGAL RELATIONSHIPS
}

Sabrine M. Santos

Paulo R. M. Menandro*

Santos SM, Menandro PRM. Relatos de mães com bebês internados em UTI Neonatal sobre relações familiares e conjugais. Rev Bras Cresc Desen Hum 2005; 15(2):22-35.

Resumo: Mães com bebês recém-nascidos internados em UTI Neonatal encontram-se em delicada espera aguardando a evolução da saúde dos filhos. Relatos obtidos em tal momento de fragilidade evidenciaram grande diversidade de situações, fugindo à expectativa de que o nascimento de um filho ocorra em condições de estabilidade e entendimento familiar/conjugal. Foram examinados 144 relatos de entrevistas de mães cujos bebês apresentavam bom prognóstico. Dados foram analisados a partir da confecção de um elenco de categorias de conteúdos sobre família, vida conjugal/amorosa, e maternidade, em procedimento de análise de conteúdo. Os resultados evidenciaram predominância de mães com até 20 anos, que não executam trabalho remunerado, com escolaridade concentrada no ensino fundamental, e que viviam uniões consensuais ou já estavam separadas quando da entrevista. A reação inicial da mãe e/ou pai do bebê à notícia da gravidez foi, predominantemente, de aceitação, apesar da interrupção da gestação ter sido cogitada como possibilidade. No caso das famílias de origem, a reação inicial foi, predominantemente, desfavorável. Constatou-se a importância de que a análise das temáticas abordadas no trabalho caminhe atrelada à análise do contexto social, econômico, cultural e familiar, implicando um repensar das práticas de análise e intervenção pertinentes.

Palavras-chave: Maternidade. Família. Relações conjugais. UTI Neonatal.

\section{INTRODUÇ̃̃O}

Apesar de ser vasta a literatura referente à família, ao casamento e à maternidade, ainda é considerável a dificuldade de acesso a dados mais diretos sobre aspectos cotidianos de tais temáticas, o que exige tempo, recursos, preparo metodológico e, principalmente, disponibilidade dos atores sociais envolvidos em condições de grande exposição pessoal.
Mães com bebês recém-nascidos que necessitaram internação em UTI Neonatal (UTIN) vivem um delicado período de espera aguardando a evolução da saúde dos filhos. No Hospital Universitário Cassiano Antônio de Moraes (HUCAM), em Vitória-ES, essas mães são assistidas pelo Serviço de Psicologia, que registra vários aspectos de suas vidas através de entrevistas individuais e atividades em grupos com outras mães em situação similar, possi-

\footnotetext{
Universidade Federal do Espírito Santo, Programa de Pós-Graduação em Psicologia. Trabalho apresentado na $34^{\mathrm{a}}$ Reunião Anual da Sociedade Brasileira de Psicologia, realizada em Ribeirão Preto/SP, de 26 a 29 de outubro de 2004. Correspondência: Paulo Rogério Meira Menandro Rua Constante Sodré, 869, Apt ${ }^{\circ} 201$ Praia do Canto Vitória, ES CEP 29055-420
} 
bilitando uma ampliação do conhecimento sobre a população atendida e sobre as condições familiares e conjugais que tais mães vivenciam.

$\mathrm{O}$ acesso ao conjunto de fichas com extratos de relatos dessas mães trouxe a possibilidade de lidar com dados sobre as temáticas acima mencionadas, ultrapassando-se dificuldades de acessibilidade e de disponibilidade dos sujeitos. Ressaltamos que as entrevistas não foram realizadas com o objetivo de subsidiar a presente investigação, mas como procedimento habitual do citado serviço de Psicologia que acompanha todas as mães (e também pais e/ou outros responsáveis) com bebês internados na UTIN, oferecendo um espaço de acolhimento e de fala, nesse momento de usual fragilidade.

Assim sendo, o trabalho buscou dados relevantes acerca do relacionamento amoroso/ conjugal, do relacionamento familiar, e sobre a maternidade, que estivessem disponíveis nas fichas, apresentando caráter documental e exploratório (ressaltando-se que não foram encontrados na literatura estudos que utilizaram procedimento similar). Como tais dados dificilmente poderiam ser obtidos com a mesma riqueza em outro contexto, acreditamos que podem contribuir para a compreensão das atuais configurações familiares e conjugais, o que justifica a realização de tal estudo. Podemos adiantar que os dados obtidos em tal situação de fragilidade evidenciam grande diversidade de situações, fugindo à expectativa de que o nascimento de um filho ocorra sempre em condições de estabilidade e entendimento familiar/ conjugal.

\section{Algumas questões conceituais e teóricas relevantes}

Apesar de ser visto como própria de nossa natureza humana, a relação de afeto e intimidade entre pais e filhos, e também entre o próprio casal, tão freqüente nos dias atuais, as- sim como o modelo de família constituído por pai, mãe e filhos, não esteve presente em todas as épocas e não se verifica em todas sociedades. Até o século XVIII, a maternidade não era valorizada socialmente, a criança não tinha status de ator social, não se falava em casamento por amor por ser ele arranjado em função de interesses das famílias.

Somente no final do século XVIII ocorreram transformações em relação à maternidade, família e relacionamento conjugal, decorrentes do advento de novas exigências sócioeconômicas associadas à industrialização, embora tal idéia ficasse dissimulada sob a ideologia de valorização da mãe, da criança e do amor romântico.

Surge nesse momento a idéia do amor materno como valor tanto natural quanto social, visto como importante para o indivíduo e para a sociedade, de forma geral. A relação conjugal começa a sofrer modificações no mundo sob influência européia, passando, gradualmente, a ser temperada pelo afeto, quando advém a prática do casamento por amor e o desprezo pelos casamentos de conveniência, e esse novo caráter assumido pelo casamento completa-se com a procriação. É quando se configura a moderna família nuclear composta por marido, esposa e filhos ${ }^{1}$.

Essa forma de constituição da família é bastante recente, estando longe de ser um modelo universal e, como tal, pode sofrer transformações e assumir novos formatos.

De fato, muitas novas configurações começam a ganhar corpo nas últimas décadas do século XX, em vários locais, inclusive no Brasil. Com o enfraquecimento do modelo de família patriarcal, extensa e hierárquica, tomado como característico da sociedade brasileira até as primeiras décadas do século XX (o que levou a uma transição de valores), e num contexto de aceleradas transformações culturais, a instituição familiar tem passado por uma série de modificações, que são concomitantes às mudan- 
ças sociais mais amplas. Embora alguns autores discordem do fato de a família patriarcal extensa ter sido predominante no Brasil há alguns séculos, e do fato de que algumas configurações atuais da família nunca terem existido antes na sociedade brasileira ${ }^{2,3,4}$, mas não se trata de ponto de vista predominante.

Samara ${ }^{4}$ discute o modelo de família patriarcal que, apesar de sempre ter sido tomado como requisito e único ângulo para compreensão da vida familiar no Brasil, no decorrer da história acabou sendo indevidamente tomado como modelo predominante em todo o país e como equivalente de família brasileira. Destaca que estudos recentes têm mostrado que este não era o único formato de família existente na época da colonização. Ela, contudo, não desconsidera o valor da família patriarcal na história da sociedade brasileira; apenas aponta para a relevância de serem levados em conta, nas pesquisas sobre família, as questões de temporalidade, etnias, grupos sociais, contextos econômicos regionais e movimento da população.

Samara ${ }^{4}$ também questiona a adequação de se falar em uma nova família no Brasil de hoje, argumentando que, já no século XVIII, em virtude do contexto econômico da época, podiam ser encontradas mulheres chefiando famílias e trabalhando fora de casa (mesmo que em atividades informais e sem abandonarem suas tradicionais funções de esposas e mães), o que dificulta a interpretação de que o gerenciamento de unidades domésticas por mulheres seria uma "nova" forma de arranjo familiar. Ressalta ainda que, já no início do século XIX, especificamente em São Paulo, eram predominantes famílias nucleares, com poucos membros, sendo a forma de organização patriarcal apenas uma das formas de composição encontrada. As uniões consensuais mostravam-se bastante presentes, mesmo com todas os argumentos e ameaças de punição da Igreja, e o casamento era uma opção apenas para uma parcela da população, fatos que apontam para a diversidade de modos de vida e de "relações familiares"'.

A instituição do casamento, ao longo da história, foi, gradativamente, perdendo seu aspecto de mantenedor das linhagens e riquezas familiares, passando a ser determinada pelos principais envolvidos: os futuros cônjuges. Trigo $^{5}$ ressalta que "inicia-se assim, um período em que a escolha matrimonial deixa de ser, fundamentalmente, assunto familiar, para tornar-se teoricamente livre e, mais do que isso, com expectativa de ter o amor como base" (p. 89). É importante considerar que nesse contexto de mudanças (que ganha mais fôlego na segunda metade do século passado), a mulher passa a ocupar um lugar diferente na relação familiar e conjugal. Com mais espaço para exercer outros papéis que não os de esposa e mãe, a mulher tem assumido outros lugares, especialmente no que se refere à profissionalização, conseguindo também um outro tipo de comunicação com o homem na esfera familiar.

Trindade ${ }^{6}$ destaca que a construção sócio-histórica da representação social de maternidade (e também de paternidade) permitiu a instituição do que se considera como modelos tradicionais de mãe e pai, em que a maternidade encontra-se voltada para os filhos e para as atividades domésticas e a paternidade para o trabalho e para o sustento da família, modelos que ainda se encontram fortemente presentes no pensamento social, assim como o modelo de família nuclear.

Contudo, as novas formas de organização familiar têm conquistado cada vez mais espaço. Brasileiro e col. ${ }^{7}$ enfatizam que a família nuclear começa a perder espaço para novos arranjos familiares que fogem do modelo tradicional. Pais separados com guarda compartilhada dos filhos, uniões consensuais, recasamentos, mães criando filhos sozinhas e chefiando famílias, avós criando netos, casamentos homossexuais, uniões estáveis que não envolvem coabitação, são apenas alguns exemplos de novos formatos de família, que produzem vári- 
os reflexos nas relações conjugais, familiares e na criação dos filhos.

Fonseca ${ }^{8}$ chama a atenção para o fato de que essas dinâmicas familiares "alternativas", apesar de não se encaixarem no modelo dominante de família, gozam de popularidade, e até de legitimidade, entre determinados setores da sociedade. Sugere também, por meio da evocação de casos etnográficos, que a hegemonia da família nuclear conjugal não se exerce com a mesma força em todas as camadas sociais.

Grzybowski ${ }^{9}$ aponta que o fenômeno do divórcio está entre os principais fatores responsáveis pelas modificações no panorama familiar, visto que acarreta uma reorganização, quer no sentido das famílias monoparentais (filhos criados apenas por suas mães e, apesar de menos comum, filhos criados apenas por seus pais), quer no sentido das famílias reconstruídas e dos recasamentos.

Berquó ${ }^{10}$ destaca, baseando-se em dados censitários, que além do divórcio, tem-se assistido na sociedade brasileira, nas últimas décadas, um aumento expressivo de casamentos não legalizados - uniões consensuais ou coabitação sem vínculos legais - havendo queda de uniões legalizadas, e também declínio dos casamentos religiosos.

A gravidez na adolescência também pode ser considerada como real possibilidade de novas formas de arranjos familiares, visto que, muitas vezes, leva a mãe adolescente a morar com o filho junto com seus pais, ou com os pais do pai do bebê, com amigas, ou então, sem os filhos, deixando-os com avós ou outros parentes por diferentes motivos. A gravidez adolescente, segundo Esteves ${ }^{11}$, é, com freqüência, tratada de forma negativa na literatura sobre o tema, tendendo-se a discutir apenas os prejuízos da gravidez para a mãe, para a criança, e para a esfera familiar. A autora apresenta as principais consequiências negativas decorrentes da gravidez na adolescência destacadas na literatura, várias delas implicando rearranjos familiares. a) impossibilidade de completar a função da adolescência, tendo que antecipar escolhas e abreviar experiências; b) abandono da vida escolar (por vergonha, proibição ou interdição de outras naturezas); c) menor chance de qualificação profissional, com óbvios reflexos para as oportunidades de inserção posterior no mundo do trabalho; d) grande dificuldade para rearticular a vida sexual e limitar a fecundidade; e) impossibilidade de estabelecer uma família com plena autonomia, autogestão e projeto de futuro; f) dependência absoluta da família ou do pai da criança; g) maior risco de instabilidade conjugal; $h$ ) abandono familiar da adolescente, em alguns casos, levando a maior empobrecimento da mesma e da família que venha constituir; i) vivência de preconceito em várias instâncias sociais; $j$ ) despreparo para lidar com o desenvolvimento do filho; l) maior risco de comprometimento da saúde física elou emocional do bebê; $m$ ) risco alto de comprometimento da saúde física elou emocional da mãe adolescente, diante das dificuldades enfrentadas no atendimento de suas próprias necessidades e carências (p. 29-30).

A autora destaca ainda que a forma como a família lida com a questão da gravidez adolescente tem reflexos diretos no funcionamento familiar como um todo, e também na forma como a adolescente lidará com as transformações advindas desse novo momento, podendo a família, então, ser pensada como fonte de apoio e suporte para enfrentamento e adaptação a situações adversas ou, em outros termos, como fonte potencial de resiliência ${ }^{11}$.

Rêgo e col. ${ }^{12}$ enfatizam que o lugar da família como fonte de resiliência tem sido negligenciado pela pesquisa, e destacam que a resiliência familiar abrange, especialmente nos momentos de crises e de estresses, os processos de desenvolvimento de capacidades básicas para promover proteção e crescimento para si e para seus membros, possibilitando a adapta- 
ção após crises ou transições, o benefício da rede de relações e recursos da comunidade e a contribuição com a mesma. O sistema de crenças, os padrões de organização familiar e os processos de comunicação também constituem processos familiares importantes na resiliência.

Bastos e col. ${ }^{13}$ argumentam que a família permite a estruturação da vida cotidiana e a constituição de redes de apoio para o indivíduo, mesmo quando os direitos humanos mais básicos não são garantidos pelas políticas públicas. Enfatizam que o contexto familiar apresenta um considerável potencial para a mudança, atuando como recurso tanto em nível individual quanto coletivo.

Tais afirmações não significam que a família pode ser considerada independentemente de um contexto sócio-cultural mais amplo pois, apesar das particularidades possíveis aos seus membros e a si própria, apresenta-se interligada à dimensão sócio-cultural, que implica normas, valores, signos e crenças compartilhadas socialmente ${ }^{13}$; também não implicam em isenção das políticas públicas no que se refere à garantia dos direitos humanos básicos, como se a família tivesse que dar conta de uma responsabilidade que nãoé sua.

A noção de resiliência familiar também pode ser considerada nos casos em que nasce um bebê com algum grau de comprometimento físico e/ou intelectual, ou quando o bebê nasce prematuramente. O nascimento de uma criança exige uma série de rearranjos por parte do casal e, muitas vezes, de toda a família, visto que um bebê requer atenção e cuidados específicos. Quando a criança apresenta algum risco de vida e tem que ficar hospitalizada (como é o caso dos bebês que ficam em UTIN), as dificuldades podem ser ainda maiores, pois a preocupação com a sobrevivência e o estado de saúde da mesma pode afetar a relação conjugal ou familiar, além de esbarrar nas representações sociais de maternidade e paternidade do casal.

Por outro lado, essa situação também pode servir, por exemplo, para a aproximação entre os pais da criança e/ou até entre estes e as famílias de origem, tendo algum resultado "favorável"; no caso da relação conjugal, Trinda$\mathrm{de}^{14}$ propõe que acontecimentos desse tipo tanto podem afastar o casal quanto aproximá-lo.

Dessen e Braz ${ }^{15}$ discutem que outros sistemas fora da família, como a vizinhança, a comunidade, a escola, o local de trabalho e a rede social, também exercem influência nas interações e no desenvolvimento dos seus membros. Apontam a importância da rede social de apoio das famílias para a manutenção do equilíbrio e da dinâmica familiar, especialmente no enfrentamento de transições, como é o que acontece com o nascimento dos filhos.

A rede social pode fornecer ao indivíduo tanto apoio instrumental (ajuda financeira, divisão de responsabilidades, etc.) quanto emocional (afeto, suporte, simpatia, preocupação, prestação de informações, etc.), e os indivíduos que integram a rede social de apoio e as funções que executam variam, segundo o contexto histórico, social e cultural, e segundo o estágio de desenvolvimento pessoal e familiar, assim como a própria rede se altera durante períodos de transições ${ }^{15}$.

A possibilidade de explorar dados sobre família, principalmente quando envolvem diretamente aspectos de relacionamento conjugal e maternidade, muito pode contribuir para o campo de estudos no qual a família constitui tema central, o que pode ser tomado com principal justificativa para a presente investigação.

\section{MÉTODOS}

O trabalho foi desenvolvido a partir de um conjunto de fichas de entrevistas reunidas em atendimento a um primeiro critério: fichas com indicação de que o bebê apresentava um bom prognóstico, ou seja, bebê com comprometimento mínimo de desenvolvimento. 
Foram disponibilizadas pelo serviço de Psicologia do Hospital Universitário Cassiano Antônio de Morais (HUCAM) todas as fichas de entrevistas arquivadas no período de setembro de 1999 até junho de 2003, somando 875 fichas com informações sócio-demográficas sobre os pais, tempo de relacionamento entre eles, aspectos da relação conjugal e familiar, além de dados sobre o bebê, a gestação e o parto. Como primeiro passo, foram excluídas as fichas que não se enquadravam no critério referido acima (tais como, aquelas de bebês que tinham ido a óbito ou com quadro muito grave). A decisão seguinte foi a de considerar apenas as fichas a partir do ano de 2001, uma vez que as dos anos anteriores eram muito pouco informativas.

Foram selecionadas 04 fichas de cada mês dos anos de 2001 e 2002 e, considerando-se que no ano de 2003 estavam disponíveis apenas as fichas de janeiro a junho, foram selecionadas 08 fichas de cada mês. Sempre que não fosse possível selecionar o número de fichas pretendido em um mesmo mês, fazia-se a compensação com o mês seguinte. No total foram selecionadas 144 fichas, privilegiando-se as que apresentavam mais dados. Ressaltamos que as fichas foram preenchidas por diferentes participantes do Serviço de Psicologia, o que implicou alterações na forma, no rigor e na consistência dos registros.

É importante mencionar que em algumas poucas fichas há registro da presença do pai do bebê no momento da entrevista, o que pode ter interferido nas respostas das mães, especialmente no que se refere ao relacionamento do casal.

A idade das mães cujas entrevistas foram selecionadas para este estudo variou de 14 a 41 anos (não foram estabelecidos limites quanto à idade das mães, pois a idade não constitui critério para seleção das fichas), sendo grande parte delas primíparas (87 mães: $60,41 \%$ ).

Para extração dos dados das fichas de entrevistas, nas quais há grande variedade de informações, foi elaborado, de acordo com os objetivos do presente trabalho, um instrumento para identificação de elementos significativos no que se refere a relacionamento amoroso, casamento, família e maternidade, buscando-se destacar os grandes temas que compareciam nas entrevistas, conforme modelo no Quadro 1.

Quadro 1 Roteiro para identificação de elementos significativos nas entrevistas

\begin{tabular}{|l} 
Roteiro para identificação de elementos \\
significativos nas entrevistas - Dados sobre \\
família, casamento e maternidade \\
1. Idade materna / paterna \\
2. Grau de escolaridade da mãe / do pai \\
3. Atividade profissional da mãe / do pai \\
4. Vinculações familiares, no de filhos... \\
5. Estágio e tempo de relacionamento - \\
namoro, casamento, "moram juntos", separados... \\
6. Reação do casal à gravidez (Gravidez \\
planejada? Tentativa de interrupção da gravidez?). \\
7. Cotidiano do casal \\
8. Relacionamento com as famílias de origem e reação das \\
famílias à gravidez - impactos,; aspectos positivos e \\
negativos assinalados; composição das famílias. \\
9. Informações sobre outras gestações \\
10. Expectativas em torno do nascimento do bebê \\
11. Suporte afetivo durante a gravidez \\
12. Suporte financeiro durante a gravidez (realização de \\
pré-natal, assistência familiar, assistência do pai do \\
bebê...).
\end{tabular}

A análise dos roteiros foi feita com base na proposta da análise de conteúdo de $\operatorname{Bardin}^{16}$, especificamente com a análise categorial (temática).

Convém mencionar que as fichas foram disponibilizadas mediante a garantia de sigilo e confidencialidade das informações nela contidas (anonimato completo das entrevistadas e garantia de ausência de risco de qualquer natureza para as mulheres cujos relatos fossem investigados), sendo ressaltado o compromisso ético do estudo e sua finalidade acadêmica, bem como garantido o acesso dos membros da equipe do Serviço de Psicologia ao relatório final. 


\section{RESULTADOS E DISCUSSÃO}

As entrevistadas com idade igual ou inferior a 20 anos representam $45,8 \%$ do total, o que está em consonância com os registros disponíveis em nível estadual e federal que apontam freqüência significativa e crescente de gravidez no período da adolescência ${ }^{11}$.

O nível de escolaridade concentrou-se basicamente no ensino fundamental (49,3\%), o que pode ter relação direta com o fato de grande parte das entrevistadas ter 20 anos ou menos e, certamente, com o fato de se tratar, predominantemente, de população de baixa renda, o que é confirmado pelos registros das fichas (condição financeira muito precária das mães e suas famílias, além dos indicadores complementares de local de residência, nível de escolaridade, atividade profissional da mãe e do pai do bebê). Informações completas sobre idade e escolaridade estão apresentadas a seguir, conforme Quadro 2.

Quadro 2 Caracterização das mães quanto à idade e grau de escolaridade

\begin{tabular}{|c|c|}
\hline Idade materna & Grau de escolaridade das mães \\
\hline $14-20$ & zada: 03 mulheres $(2,3 \%)$ \\
\hline mulheres $(45,8 \%)$ & Até $4^{\mathrm{a}}$ série: 19 mulheres $(13,2 \%)$ \\
\hline 21-30 anos: 67 & $5^{\mathrm{a}}-8^{\mathrm{a}}$ série: 71 mulheres $(49,3 \%)$ \\
\hline mulheres $(46,5 \%)$ & $2^{\circ}$ grau incompleto: 31 mulheres $(21,5 \%$ \\
\hline 31-40 anos: 10 & $2^{\circ}$ grau completo: 18 mulheres $(12,5 \%)$ \\
\hline mulheres $(7,0 \%)$ & $3^{\circ}$ grau incompleto: 01 mulher $(0,6 \%)$ \\
\hline $\begin{array}{l}\text { Acima de } 40 \text { anos: } \\
01 \text { mulher }(0,7 \%)\end{array}$ & Não revelado: 01 mulher $(0,6 \%)$ \\
\hline
\end{tabular}

A grande maioria das entrevistadas $(69.4 \%)$ não exercia qualquer tipo de atividade remunerada no momento das entrevistas, o que sugere que tinham apoio financeiro do pai do bebê, de familiares ou equivalentes. Também é possível perceber que as atividades exercidas são compatíveis com o nível de escolaridade apresentado sendo, em geral, atividades que requerem pouca instrução. As atividades que foram mencionadas mais de uma vez foram: doméstica/faxineira: 14 vezes; balconista: 04; professora: 04; auxiliar administrativo: 02; au- xiliar de serviços gerais: 02; lavradora: 02 .

Como se mostrou bastante expressivo o conjunto de mães com 20 anos ou menos, foi possível a configuração de dois grupos tomando como base a idade materna: o das mães com até 20 anos e o das mães com 21 anos ou mais.

Merece destaque o cruzamento da idade materna como estágio de relacionamento com o pai do bebê no momento da entrevista, como destacado no Quadro 3.

Percebe-se que o número de mães com 20 anos ou menos que declararam união consensual ("morar junto"; "ser juntada") é expressivo (28 mães: 42,4\%), o que também ocorre em relação à continuidade do namoro (16 mães: 24,2\%). Já os casamentos formalizados somaram apenas 03 casos $(4,5 \%)$. No grupo de mães com 21 anos ou mais a situação não é muito diferente: 27 casos de união consensual $(34,6 \%)$; 07 casos de namoro continuado $(9,0 \%)$; e 08 casos de casamentos $(10,3 \%)$. Isso corrobora dados da literatura que apontam que as uniões legais têm, cada vez mais, perdido espaço para as uniões consensuais e para outras formas de arranjo familiar.

Berquó $^{10}$ entende que a ocorrência precoce de gravidez em jovens pode originar mudanças no curso de suas vidas, culminando, em muitos casos, com uniões precoces, sejam legalizadas ou não. Essa autora constata que a proporção de uniões não legalizadas é muito elevada no Brasil, alertando para o fato de que

Estes resultados podem estar mostrando ou certa recusa por parte dos jovens à formalização de uma união, ou a presença de uniões "experimentais" que se formalizariam no futuro, ou ambos. Não se deve perder de vista também o custo do casamento civil, elevado para certas camadas da população (p. 96).

Bastos e col. ${ }^{13}$ comentam que o emprego, no caso do menino, e a maternidade, no caso da menina, em contextos sócio-econômi- 
Quadro 3 Estágio de relacionamento com o pai do bebê, considerando a idade materna.

\begin{tabular}{|c|c|c|}
\hline & \multicolumn{2}{|c|}{ Idade das mães } \\
\hline $\begin{array}{l}\text { Estágio de relacionamento com o pai } \\
\text { do bebê }\end{array}$ & $\begin{array}{l}\text { Mães com até } 20 \\
\text { anos }(66)\end{array}$ & $\begin{array}{c}\text { Mães com } 21 \text { anos ou mais } \\
\text { (78) }\end{array}$ \\
\hline Moram juntos/ "juntados" & 28 mães $\quad(42,4 \%)$ & $\begin{array}{l}27 \text { mães (incluindo uma que está } \\
\text { pensando em se separar).(34,6\%) }\end{array}$ \\
\hline Estão separados/separando-se & $\begin{array}{l}17 \text { mães (incluindo } \\
02 \text { que têm outro } \\
\text { relacionamento) } \\
(25,7 \%)\end{array}$ & $\begin{array}{l}29 \text { mães (incluindo: tem outro } \\
\text { relacionamento: 01; ficaram } \\
\text { juntos apenas algumas vezes: 01; } \\
\text { tiveram uma única relação } \\
\text { sexual: 01; } \\
\text { temporariamente em casan } \\
\text { separadas, pois ela pediu um } \\
\text { tempo: 01; pai do bebê faleceu: } \\
01) \text {. }\end{array}$ \\
\hline Casados & 03 mães & 08 mães \\
\hline Namoram & 16 mães & 07 mães \\
\hline Relacionamento em segredo & 01 mãe & - \\
\hline $\begin{array}{l}\text { Relacionamento não muito sério } \\
\text { ("rolo")/ "sem compromisso" }\end{array}$ & 01 mãe & 01 mãe \\
\hline $\begin{array}{l}\begin{array}{l}\text { Indefinido ("não sabe como vai } \\
\text { ficar"): }\end{array} \\
\end{array}$ & - & 02 mães \\
\hline São amantes & - & 02 mães \\
\hline $\begin{array}{l}\text { Estão juntos, mas o companheiro } \\
\text { está (estava) preso }\end{array}$ & - & 02 mães \\
\hline
\end{tabular}

cos precários, podem mostrar-se altamente atraentes na medida em que os adolescentes, em sua idade, não encontram outros caminhos mais favoráveis. Esteves ${ }^{11}$ corrobora tal afirmação, enfatizando que adolescentes de camadas sócio-econômicas marcadas pela exclusão social podem ver na maternidade a possibilidade de mudanças em seu status social.

Esteves $^{13}$ discute, em seu estudo sobre gravidez adolescente, que o tipo de inserção sócio-econômica deve ser levado em conta na análise da gravidez adolescente e de sua repercussão na vida das jovens mães, até porque o processo de adolescência não é experienciado de forma igual por todas pessoas e por todos os estratos sociais.

É interessante perceber também que, no momento em que a entrevista foi realizada (sempre logo após o parto e a internação do bebê na UTIN), muitas mulheres (46:31,9\%) já estavam separadas do pai do bebê (que, em muitos casos, não queria contato com a mãe e/ou com a criança). Tal fato contrasta com a idéia bastante difundida no senso comum de que o nascimento de um bebê é normalmente um momento culminante de aproximação entre os pais, envolvendo também os demais membros da família.

Os motivos de separação relatados foram os mais diversos (em dois casos o motivo de separação não aparece claramente especificado). Houve grande diversidade de razões apresentadas, e essas foram classificadas nas seguintes categorias: 1) uso de álcool / drogas por parte do companheiro e/ou violência doméstica; 2) brigas constantes com o companheiro e, em alguns casos, envolvendo a família de origem dele; 3) relação instável/problemas diversos no relacionamento; 4) ele tem outra mulher; 5) reação negativa do companheiro ao anúncio da gravidez/dúvida quanto à paternidade; 6) ele 
não confiava nela/achava que era traído; 7) descobriu na gravidez que pegou sífilis do companheiro (e o bebê foi contaminado); 8) enjoou do namorado após a gravidez;9) ela ainda gosta de um ex-namorado; 10) ele não gosta mais dela; 11) vinculação religiosa do companheiro e exigências da mesma; 12) consideram-se apenas amigos; 13) o pai do bebê foi assassinado; 14) estava/está se relacionando com outro e não sabe com quem quer ficar; 15) ele foi trabalhar em outra cidade e a ex-mulher dele estava pressionando.

Convém ressaltar que em quatro casos as razões de separação apresentadas englobam duas categorias distintas, como no exemplo: "o pai do bebê bebia e usava drogas, e diz que o filho nãoé dele", que engloba as categorias 1 e 5.

Em muitos casos o motivo dado para a separação está relacionado com o uso de álcool, de outras drogas e com a violência doméstica, além de ser possível encontrar nas entrevistas várias referências à dificuldade de relacionamento com familiares (mãe, pai, irmãos, cunhados, sogra, padrasto, entre outros) em virtude de tais práticas. Em duas entrevistas, há menção à tentativa de abuso sexual da entrevistada quando criança, por parte de pessoas próximas (padrasto e avô) e, em um caso, a entrevistada foi vítima de estupro pelo pai. $\mathrm{O}$ caso específico de violência doméstica configura-se em 24 entrevistas. Dados mais detalhados sobre a presença de bebida alcoólica ou outras drogas como parte do contexto familiar ou conjugal são apresentados no Quadro 4.

Algumas mães também relataram ter feito uso de álcool e drogas durante a gestação.
Mello e col. ${ }^{17}$ apontam que o uso de tais substâncias durante a gestação pode trazer sérias conseqüências, colocando-se como um dos fatores predisponentes para a prematuridade $\mathrm{e}$ baixo peso. Também destacam como fatores predisponentes

\section{(...) a idade materna (abaixo de 16} anos e acima de 40 anos), primiparidade, adolescentes solteiras, pequeno intervalo entre as gestações, má nutrição materna, algumas patologias (hipertensão arterial, cardiopatias, diabetes, intercorrências obstétricas, entre outras), ausência de cuidado pré-natal, fumo, consumo de álcool e drogas, riscos ocupacionais, baixo nível de escolaridade materna e situação sócio-econômica desfavorável. Muitas causas do nascimento prematuro e do baixo peso ao nascer são desconhecidas (p. 50).

O cuidado pré-natal que, quando ausente, também é considerado fator predisponente, não aparece revelado na maioria das entrevistas. Apenas nove fichas trazem tal informação declarada, e em quatro, há menção à impossibilidade de realização do acompanhamento prénatal.

É interessante ressaltar a forma como a maternidade foi experienciada desde o início, explorando-se a reação inicial diante da constatação da gravidez pela mãe e/ou pai do bebê (independentemente de ser ou não primeiro fi1ho). Nesse caso, optou-se pela criação de algumas categorias que pudessem englobar as diversas reações citadas, considerando-se que, em várias fichas, não há menção à reação inicial. No caso das mães com até 20 anos, 42 fi-

Quadro 4 Presença de bebida alcoólica ou outras drogas no contexto conjugal/familiar.

\begin{tabular}{|l|c|c|}
\hline \multicolumn{1}{|c|}{ Usuário de drogas e/ou álcool } & $\begin{array}{c}\mathrm{N}^{\circ} \text { de } \\
\text { ocorrências }\end{array}$ & $\begin{array}{c}\text { \% sobre o total de casos de } \\
\text { separação (N=46) }\end{array}$ \\
\hline $\begin{array}{l}\text { O companheiro atual ou um ex-companheiro faz ou } \\
\text { fez uso drogas e/ou bebida alcoólica. }\end{array}$ & 24 & $52,2 \%$ \\
\hline $\begin{array}{l}\text { Alguém da família faz uso de drogas e/ou bebida } \\
\text { alcoólica. }\end{array}$ & 22 & $47,8 \%$ \\
\hline $\begin{array}{l}\text { A entrevistada faz ou fez uso de drogas e/ou bebida } \\
\text { alcoólica. }\end{array}$ & 8 & $17,4 \%$ \\
\hline
\end{tabular}


chas trouxeram informações sobre a reação inicial, o que também se verificou em 44 fichas do grupo de mães com 21 anos ou mais, como se pode observar no Quadro 5.

Quadro 5 Reação da mãe e/ou pai do bebê à gravidez

\begin{tabular}{|l|c|c|}
\hline \multicolumn{1}{|c|}{ Reação inicial à gravidez } & Mães com até 20 anos & $\begin{array}{c}\text { Mães com 21 anos ou } \\
\text { mais }\end{array}$ \\
\hline $\begin{array}{l}\text { 1. Recepção negativa e/ou referência à } \\
\text { possibilidade de interrupção da gestação }\end{array}$ & 10 & 13 \\
\hline $\begin{array}{l}\text { 2. Aceitação da gravidez - referência a uma } \\
\text { gravidez "acidental” / não planejada, mas sem } \\
\text { menção à possibilidade de interrupção }\end{array}$ & 25 & 22 \\
\hline 3. Gravidez planejada / recepção positiva & & 08 \\
\hline 4. Gravidez planejada / recepção negativa & 05 & 01 \\
\hline
\end{tabular}

Nos dois grupos, percebe-se que a reação inicial é, predominantemente, de aceitação, apesar da gravidez não ter sido planejada. Em se tratando especificamente do grupo de mães adolescentes, tal fato "vem de certa forma desmistificar a idéia de que a maternidade na adolescência é sempre desfavorável na vida destas jovens" 18 .

Contudo, é inegável que o número de mulheres que pensaram em ou tentaram, de fato, interromper a gravidez é bastante considerável em ambos os grupos, o que esbarra na idéia ainda vigente de instinto materno. A possibilidade de aborto com a descoberta da gravidez aparece explicitada nos relatos de 15 mães, incluindo as mães que só pensaram em fazê-lo e as que tentaram de fato abortar. Apesar de menos numerosos, há também casos nos quais quem propôs o aborto foi o pai do bebê ou a avó materna.

Pareceu-nos interessante trazer alguns exemplos de reações negativas à gravidez com referência à possibilidade de interrupção da gestação, sem separá-los de acordo com a idade materna: pensou em fazer aborto, pois temia a reação da família com o anúncio da gravidez; tentou abortar de várias formas (tomou chás, bebida alcoólica, batia na barriga), mas o namorado não queria o aborto, apesar de ter ficado assustado com a notícia; ela só não realizou o aborto porque queria chantagear o na- morado; eles não queriam este bebê - ele exigiu que ela tirasse e ela também queria tirar (tomou chás, mas não teve coragem de tomar $\mathrm{Ci}^{-}$ totec); ela queria "tirar", pois um bebê a atrapalha ir aos bailes funks, mas o namorado não queria e ela repensou (gravidez não planejada); ela queria que o bebê fosse filho do marido que morreu e pensou em abortar, pois planejava outras coisas para sua vida; pensou em abortar porque está separada e começando a trabalhar, e só não o fez porque teve medo que algum dos seus outros filhos fosse castigado por Deus.

Cabe destacar que as mães que relataram ausência de planejamento da gravidez (gravidez acidental), em sua maioria, revelaram não fazer uso de qualquer método contraceptivo, mesmo aquelas com relacionamentos instáveis. Além disso, não demonstraram qualquer preocupação referente à contaminação por doenças sexualmente transmissíveis, mesmo quando indagadas a este respeito (há um caso em que a mãe e o pai do bebê são HIV+ e não fazem tratamento, e já tinham um bebê de um ano e oito meses HIV+, o vírus tendo sido passado pela amamentação, mesmo ela sabendo do risco de transmissão; a mãe do bebê também tem sífilis). Algumas mães alegaram que esqueceram da camisinha ou do remédio "naquela vez" ou que pediam para os parceiros usarem camisinha ou comprarem anticoncepcional, mas estes não o faziam, mesmo não querendo uma 
gravidez naquele momento, de modo que elas atribuem a gravidez a tal fato, isentando-se da responsabilidade.

Tal situação é preocupante e nos leva a pensar se, de fato, as inúmeras campanhas de prevenção às drogas e DST's/Aids, por exemplo, têm alcançado repercussão nessa parcela da população e no contexto do qual fazem parte.

Em seis casos, há menção à reação negativa dos parceiros diante da notícia da gravidez, comparecendo propostas deles de interrupção da gestação em três relatos. Há também diversos relatos em que aparece a desconfiança do parceiro com relação à paternidade da criança, geralmente, seguida de abandono da mãe e do bebê.

No caso da reação das famílias de origem à comunicação da gravidez, (considerando-se também aqui que tal informação não aparece explicitada em muitas fichas), encontramos que, de modo predominante, a recepção da notícia da gravidez pelas famílias de origem é marcada pela crítica, indiferença, discussão, prevalecendo reações iniciais desfavoráveis. A recepção positiva envolvendo apoio e acolhimento aparece de forma menos acentuada, estando presente em apenas 10 relatos. Tal situação pode ter relação com o fato de que está em jogo um grande número de mães jovens que, em muitos casos, ainda moram com suas famílias e são dependentes financeiramente dos pais. Contudo, tal tipo de reação não se mostrou exclusiva das famílias das mães com até 20 anos, comparecendo também no grupo de mães com 21 anos ou mais, o que mostra que a reação negativa também tem relação com fatores de outra natureza.

Como exemplos de reação negativa à gravidez por parte das famílias de origem podemos citar: a mãe dela sugeriu que ela abortasse; a família reagiu muito mal à notícia da gravidez; a mãe dela mandou que ela saísse de casa e se virasse com o bebê, mas o pai dela permitiu que continuasse lá; a mãe dela bateu nela quando ela ficou grávida e foi morar com o pai do bebê; a mãe dela a expulsou de casa quando soube que ela estava grávida de um "vagabundo"; a família dela não estava aceitando a gravidez no início porque o pai do bebê é casado e a família é muito tradicional e severa; a mãe dela ficou dois meses sem conversar "direito" com ela por causa da gravidez; ela escondeu a gravidez até o $5^{\circ}$ mês com medo de que a família brigasse e quando contou, a família brigou, mas aceitou; a família do pai do bebê ficou "envenenando", dizendo que o filho não é dele; a mãe do pai do bebê disse que tinha que esperar o bebê nascer para ver a cara dele e saber se é mesmo neto dela.

Silva e Salomão ${ }^{18}$, em estudo sobre maternidade na perspectiva de mães adolescentes e de avós maternas dos bebês, constataram que as reações iniciais frente à notícia da gravidez, tanto no caso das adolescentes quanto das avós (suas mães), foram desfavoráveis, especialmente para as segundas. Verificaram também, nos relatos das jovens mães, menções a tentativas de aborto, quer por vontade própria, quer por indução das avós maternas dos bebês.

Apesar de mostrar-se presente nos discursos de um número reduzido de mães, o processo de resiliência familiar aparece explicitado na forma de apoio da família e de certos rearranjos por parte da mesma para o acolhimento da criança e sua mãe e para a proteção e crescimento para si e seus membros (por exemplo, maior aproximação entre mãe e filha, construção de um cômodo para que a mãe possa viver com seu bebê e parceiro).

Nos relatos de várias mães aparece a questão de sua responsabilização quase que absoluta pelo bebê, não só no período de internação, mas com relação à criação futura da criança. Algumas chegaram a falar que não mais importava o pai do bebê, "agora seriam apenas ela e a criança". Tais relatos mostram a dificuldade das mães de dividir com o pai as responsabilidades relativas ao bebê e de colocá-lo em 
um lugar de importância com relação à criança, fato que pode ter relação com representações tradicionais de maternidade e paternidade, nas quais a mãe é entendida como responsável principal ou única pela criança.

É interessante notar que não aparecem nas entrevistas muitos dados sobre expectativas em relação ao bebê, sentimentos em relação aos mesmos, sendo freqüentes as menções à expectativa de que "o bebê vá logo para casa", "melhore o mais rápido possível", ,fique bem", enfim, preocupações vinculadas à saída do bebê do hospital e ao seu estado de saúde. Tal fato pode ter relação com o contexto muito específico em que os dados foram coletados. Contudo, há casos em que a mãe coloca o nascimento do bebê como um acontecimento que irá mudar sua vida radicalmente.

Os resultados da presente investigação, considerando as características das participantes e o contexto de coleta de dados, não são apropriados para generalizações sobre maternidade, relacionamento conjugal e família, mas constituem achados que podem servir como "disparadores" para novos estudos sobre as temáticas abordadas, além de informarem sobre peculiaridades de possível interesse para a pesquisa sobre os temas que foram considerados.

\section{CONSIDERAÇÕES FINAIS}

A forma como as mulheres compreendem e vivenciam a experiência da maternidade e o relacionamento conjugal está sofrendo alterações nas últimas décadas, apesar da grande difusão e aceitação da noção de instinto materno e do modelo de família nuclear. O peso sobre a mulher/mãe ainda é muito grande, visto que permanece a idéia da mulher como única ou principal responsável pelos filhos (como propõe o mito do amor materno) e também pela "prevenção" dos mesmos (elas é que devem "evitar" os filhos), sendo, muitas vezes, "abandonadas" pelo pai da criança, que não se vê como responsável direto.

Em se tratando da gravidez na adolescência as complicações podem ser ainda maiores pois, em muitos casos, os parceiros também são adolescentes, o que pode comprometer ainda mais a vivência deste momento, já que nem sempre os adolescentes têm condições (em termos financeiros e de maturidade) de assumir a responsabilidade de cuidar de um bebê e constituir uma família, o que, obviamente, não pode ser tomado como regra geral.

Neste contexto, a família apresenta um papel fundamental, pois pode atuar como fonte de apoio, acolhendo a adolescente grávida e o bebê (e até mesmo o pai da criança), ou dando condições para que eles vivenciem esse período da melhor forma possível. Entretanto, isso nem sempre acontece pois, muitas vezes, a reação das famílias à gravidez e ao nascimento da criança é desfavorável, como no caso do presente estudo. Também é comum nesta situação a família pressionar para que a adolescente se una, independente de sua vontade, ao pai do bebê, seja através de um vínculo formal (matrimônio), seja a partir da simples divisão do mesmo domicílio (muitas vezes, a própria casa dos pais).

No presente estudo fica evidente o posicionamento predominantemente negativo das famílias de origem frente à descoberta da gravidez (não só no caso das adolescentes), o que talvez tenha relação com a questão das circunstâncias em que a gravidez ocorre (o pai do bebê é casado; a família não tem uma boa relação com o pai da criança; a filha é considerada muito jovem para ter um filho; há dúvidas com relação à paternidade da criança por parte da família do pai do bebê; entre outras coisas), e também com o contexto sócio-econômico em que estão inseridas.

Esteves ${ }^{11}$ propõe que

(...) as repercussões de uma gravidez. adolescente não devem ser pensadas, exclusivamente, a partir do conjunto de exigênci- 
as e responsabilidades impostas a quem a vivencia, mas exigem compreensão de como características do contexto cultural e sócioeconômico em que a família (ou similar) da grávida está imersa modulam tais repercussões (p.188-9).

As mães do presente estudo estavam com seus bebês internados em uma UTI Neonatal, o que pode interferir muito na forma como vivenciam o nascimento do bebê. O contato com uma criança abaixo do peso, pequena, com algum comprometimento de saúde e que não pode ficar com ela logo após seu nascimento, muitas vezes esbarra na representação que as mulheres trazem de um bebê recém-nascido e do período pós-parto, fato que pode gerar angústia e confusão de sentimentos em tais mães que não sabem como se comportar frente a esse bebê "diferente".

Além disso, os resultados apontam que o fato de o bebê ter nascido prematuro e/ou com problemas não é visto pelas mães, de uma forma geral, como promotor de um estreitamento dos laços entre o casal ou de uma aproximação entre os pais da criança e as famílias de origem; em muitos casos, a simples descoberta da gravidez levou à separação do casal ou ao afastamento das famílias.

Nesse sentido, o fato de estar separada do pai da criança no momento do seu nasci- mento (como é o caso de grande número das entrevistadas deste estudo) também deve ser visto como fator que influencia diretamente a maneira como as mulheres experienciam tal momento e, consequentemente, falam do mesmo, pois fica a expectativa de que elas terão que enfrentar essa situação sem o apoio e ajuda do companheiro e de que o filho poderá crescer "sem pai" - pai esse que, em muitos casos, deixou claro que não irá registrar o bebê e ajudar financeiramente, muitas vezes, até por exigência da própria mãe da criança. Além disso, no caso daquelas mães em que a mãe ou alguém muito próxima viveu experiência semelhante e encontrou muita dificuldade, fica o receio de que a história acabe se repetindo com ela, até porque, normalmente, as circunstâncias (o contexto) têm grande chance de serem as mesmas.

Diante dessas considerações, percebese que a análise das temáticas abordadas no presente trabalho deve caminhar atrelada a uma análise do contexto social, econômico, cultural e familiar visto que, em meio a uma série de transformações no panorama brasileiro nas últimas décadas, instituições como família, casamento e maternidade não ficaram imunes, o que exige um repensar de nossas práticas de análise e intervenção em relação aos processos implicados em tais temáticas.

\begin{abstract}
Mothers with newborn babies submitted to intensive care at hospital units find themselves in a delicate situation while waiting for the evolution of their children's health. Reports obtained in such a fragile moment revealed a great diversity of situations, diverging from the expectation that a child's birth occurs under conditions of stability and familial/conjugal understanding. An amount of 144 reports from interviews of mothers whose babies presented a good prognosis were examined. Data were analyzed based on a set of content categories about family, conjugal/love life, and motherhood, in a content analysis procedure. The results show the predominance of mothers less than 20 years old, who do not perform paid work, with formal education concentrated in the elementary and junior high school levels, and who lived consensual relationships or were already separated when the interview took place. The mothers' and fathers' initial reaction to the pregnancy news was of acceptance, although the idea of interruption was considered. In the case of the origin families, the initial reaction was, predominantly, unfavorable. This study showed that it is important that the analysis of the theme studied in this work is linked to the analysis of the social, economic, cultural, and familial context, implying a rethinking of the pertinent analysis and intervention practices.
\end{abstract}


Key words: Motherhood. Family. Conjugal relationship. Newborn ICU.

\section{REFERÊNCIAS}

1. Badinter E. Um amor conquistado. O mito do amor materno. Rio de Janeiro: Nova Fronteira; 1985.

2. Corrêa M. Repensando a família patriarcal brasileira. In: Arantes AA, organizador. Colcha de retalhos: estudos sobre a família no Brasil. Campinas: Editora da UNICAMP, 1993. p.15-42.

3. Samara EM. Tendências atuais da história da família no Brasil. In: Almeida AMM, organizador. Pensando a família no Brasil: da colônia à atual idade. Rio de Janeiro: Espaço e Tempo; 1987. p. 25-36.

4. Samara EM. O que mudou na família brasileira? (Da colônia à atualidade). Psicologia USP 2002; 13(2): 27-48.

5. Trigo MHB. Amor e casamento no século XX. In: D’Incao MA, organizador. Amor e família no Brasil. São Paulo: Contexto; 1989. p. 88-94.

6. Trindade ZA. Concepções de maternidade e pa ternidade: O convívio atual com fantasmas do século XVIII. In: Souza L, Feitas MFQ, Rodrigues, MMP (organizadores). Psicologia: Reflexões (im)pertinentes. São Paulo: Casa do Psicólogo; 1998. p. 129-55.

7. Brasileiro RF, Jablonski B, Féres-Carneiro T. Pa péis de gênero, transição para a paternalidade e a questão da tradicionalização. Psico 2002; 33(2): 289-310.

8. Fonseca C. Mãe é uma só? Reflexões em torno de alguns casos brasileiros. Psicologia USP 2002; 13(2): 49-68.

9. Grzybowski LS. Famílias monoparentais: Mulheres divorciadas chefes de família. In. Wagner A, coordenador. Família em cena: tramas, dramas e trans formações. Petrópolis: Vozes; 2002. p. 39-53.

10. Berquó E. Quando, como e com quem se casam os jovens brasileiros. In. Jovens acontecendo nas trilhas das políticas públicas - Comissão Nacio nal de População e Desenvolvimento.

Campinas(SP): Núcleo de Estudos de População - NEPO/Unicamp; 1998. p. 93-106.

11. Esteves JR. Trajetórias de vida: Repercussões da gravidez adolescente na biografia de mulheres que viveram tal experiência [dissertação]. Vitória(ES): Programa de Pós-Graduação em Psi cologia, Universidade Federal do Espírito Santo; 2003.

12. Rêgo NN, Bastos ACS, Alcântara MAR. As mul heres da família: Mundos partilhados, mundos em conflito. Paidéia 2002; 12(22): 27-37.

13. Bastos ACS, Alcântara MAR, Ferreira-Santos JE. Novas famílias urbanas. In: Lordelo ER, Carvalho AMA, Koller ESH, organizadoras. Infância brasileira e contextos de desenvolvimento. São Paulo: Casa do Psicólogo; Salvador: Ed. Univer sidade Federal da Bahia; 2002. p. 99-135.

14. Trindade ZA. As representações sociais da maternidade e da paternidade: Implicações no processo de aconselhamento genético[tese]. São Paulo(SP): Instituto de Psicologia, Universidade de São Paulo, 1991.

15. Dessen MA, Braz MP. Rede social de apoio du rante transições decorrentes do nascimento de filhos. Psicologia: Teoria e Pesquisa 2000; 16(3): 221-31.

16. Bardin L. Análise de conteúdo. Lisboa: Edições 70; 2000.

17. Mello DF, Rocha SMM, Scochi CGS, Lima RAG. O cuidado da enfermagem no seguimento de cri anças pré-termo e de baixo peso ao nascer. Rev Bras Cresc Desen Hum 2000; 10(1): 49-60.

18. Silva DV, Salomão NR. A maternidade na perspec tiva de mães adolescentes e avós maternas dos bebês. Estudos de Psicologia 2003; 8 (1): 135-45. 